Original Article

Volume: 6 Issue: 1 pp:29-41 2019
Journal of Athletic Performance and Nutrition https://doi.org/10.31131/japn-2019-0001/3

\title{
The Influence of Functional Abilities and Morphological Characteristics on Success in
}

\section{Apnea}

\author{
Bojan Stankoviçç, Sladana Stankoviç ${ }^{1}$, Aleksandra Aleksiç Veljkoviç ${ }^{1 *}$, Marija \\ Stajanoviç ${ }^{1}$
}

Received Date: 25.01.2019

Accepted Date: 25.05.2019

\begin{abstract}
Objectives: The main goal of this research was to determine to what extent the competitors' functional abilities and morphological characteristics hypothetically explain the results achieved in static and dynamic apnea and offer a prediction.

Methods: The study included 35 artistic swimmers, body height of $162.98 \pm 5.252 \mathrm{~cm}$ and body weight of $51.47 \pm 5.578 \mathrm{~kg}$ that are in the regular training process and compete in the junior competitions. Morphological characteristic variables were obtained by analyzing the subjects' body composition by the bioelectric impedance method (BIA). Variables for the functional abilities assessment were determined by two tests: forced vital capacity (FVC) and forced expiratory volume (FEV). The influence of functional abilities and morphological characteristics on the results in static and dynamic apnea was assessed by regression analysis.

Results: The results show that functional abilities and morphological characteristics have the significantly influence on the diving results.

Conclusion: These results are important for the selection and effective training during the training period and can influence the appropriate specific training programs development. They can be use for the optimal preparation of all competitors in water sports (swimmers, water polo players, artistic swimmers and athletes practicing apnea).

Key words: Static and dynamic apnea, forced vital capacity, forced expiratory volume, artistic swimmers.

*Corresponding Author: Aleksandra Aleksic Veljkovic, Faculty of Sport and Physical Education, University of Nis, Serbia, axy.gym@gmail.com

\section{Introduction}

Diving and apnea work, in addition to being a very popular recreational, entertainment and leisure activity today, represented the only way to get food for thousands of years. Today diving is an extreme sport where people compete internationally and break records in various disciplines. Divers move the boundaries of their body possibilities through psychological, thermal (Ferretti \& Costa, 2003), morphological, respiratory and cardiovascular adaptations
\end{abstract}


(Lindholm \& Lundgren, 2008). The ability of the human body to continually adapt is surprising. It is known that staying in the water produces positive effects on the lungs by increasing lung capacity and improving lung function (Stanković, Milanović, \& Marković, 2015).

Changes in lung capacity during exercise were examined in a large number of studies (Orellana, Centeno, Carranza, \& Cayetano, 2006; Quan et al., 2010; Vaithiyanadane, Sugapriya, Saravanan, \& Ramachandran, 2012; Hayriye Çakır, 2017). With the development of new research technologies, new opportunities are created for improve getting information that are acquired for the sport system. Most of the experts and scientists involved in the athletes' morphology consider that there is a direct relationship between the sport one deals with and its morphological characteristics (Dodigović \& Sindik, 2015; Robertson, Benardot, \& Mountjoy, 2014b; Robinson \& Ferraro, 2004; Sundgot-Borgen \& Garthe, 2011). In most cases, athletes choose the sport that most suited to their morphology, because morphology is, in a way, their bodily advantage. A large number of studies prove that, the better the sporting results, the more closely they are related to the athletes' body composition (Benefice \& Malina, 1996; Dodigović $\&$ Sindik, 2015; Pyne \& Sharp, 2014). Therefore, in most sports, considerable attention is paid to observing and studying the anthropological characteristics of athletes (Benefice \& Malina, 1996).

Knowing the individual swimmers' characteristics, who actively practice apnea, is a necessary precondition for the successful development of high-quality programs that will manage the training process (Dodigović \& Sindik, 2015; Stanković et al., 2015; Kafkas, Eken, Fahri Safa, \& Kafkas, 2016). One of the sports where apnea is an integral part of the training and competition is synchronized swimming. By performing figures and compositions, swimmers move in horizontal and vertical positions in which they realize various techniques of strokes and rotation. By performing compositions, swimmers consume $33.1 \%$ of about $40 \%$ of the time in changes in the horizontal position and $72.4 \%$ of the $60 \%$ work in different vertical position options, in which movements are performed without air, with certain music and matching with other swimmers (Alentejano, Bell, \& Marshall, 2012). This kind of work in apnea requires the swimmer to have certain functional abilities and morphological characteristics (Dodigović \& Sindik, 2015; Sundgot-Borgen \& Garthe, 2011; Tanaka et al., 2006). High swimmers' performances in apnea are the result of long-term planned and systematically organized training. The construction period of these performances is divided and each of them has its own specific goals. The swimmers begin their physical preparation in the period from the sixth to the eighth year (Stanković et al., 2015; Tanaka et al., 2006). An increase in pulmonary function during growth produces an increase in aerobic capacity (Armstrong, 
Tomkinson, \& Ekelund, 2011). Functional abilities increase until physical maturity is reached. It is known that functional indicators are significantly associated with morphological characteristics.

Artistic swimming and apnea work have not been adequately studied, primarily due to difficulties in collecting data under water. Information related to functional abilities and morphological characteristics in apnea work is scarce as well as information on their influence on results in static and dynamic apnea (Stanković et al., 2015). Competition disciplines in artistic swimming are solo, duet, team, combination and highlight. In all of these disciplines, swimmers perform most of the composition underwater (Winiarski, Dubiel-Wuchowicz, \& Rutkowska-Kucharska, 2013). Consequently, swimmer training includes a large part of apnea work (Quan et al., 2010; Winiarski et al., 2013). The aim of the research is to determine the influence of swimmers' morphological characteristics and functional abilities indicators on the achieved apnea result. Competition disciplines static (STA) and dynamic apnea (DNF) were used.

\section{Methods}

\section{Sample of participants}

The study included 35 artistic swimmers, aged 17-18 years, body height of $162.98 \pm$ $5.25 \mathrm{~cm}$ and weight of $51.47 \pm 5.58 \mathrm{~kg}$, which are in regular training and compete in the junior competition for the Synchronized Swimming of Serbia.

\section{Sample of measurement}

Body structure assessment variables: body height $(\mathrm{BH})$, body mass (BM), Body Mass Index (BMI), the amount of fat in the body (Body fat \%) and percentage of muscle mass (Muscle \%). The respondents body composition assessment was carried out according to a method recommended by the International Biological Program (Weiner \& Lourie, 1969).

Functional abilities assessment variables: Forced Vital Capacity (FVC) that represents the amount of air that is pushed out of the lungs by maximal expiration after the maximum inspiration. After the maximum inhale, the subject suddenly exhales all the air, with all her strength, as strong and fast as she can (the result is read in liters). The Forced Expiratory Volume (FEV) in the first second, representing the amount of air that exhales during the first second of the forced expiration. The procedure is the same as with FVC. The value of the obtained result is expressed in liters. Measurement for each subject individually was realized with a spirometer (Vicatest P2A, Mijnhard, Netherlands). 
Criteria Variables: Static Apnea (STA) and Dynamic Apnea without Feathers (DNF) According to AIDA - International Association for the Development of Apnea.

\section{Data analysis}

Data processing was performed in SPSS 20.0. The results of this study were processed to obtain information on central and dispersion parameters for all investigated variables: Arithmetic Mean, Standard Deviation (SD), Variation Width (Min-Max), Skjunis (Skew.) and Kurtosis (Kurt.). In order to determine the influence of body composition and functional abilities on results in static and dynamic apnea, Regression analysis was applied.

\section{Results}

Descriptive indicators of the participants of the first group are shown in Table 1. The average height of the participants is $162.98 \pm 5.25 \mathrm{~cm}$, while the body weight is $51.47 \pm 5.57$ $\mathrm{kg}$. The lowest respondent was $149.00 \mathrm{~cm}$ high and $172 \mathrm{~cm}$ high. The average value of the body mass index was $19.22 \mathrm{~kg} / \mathrm{m}^{2}$. The amount of body fat (BODF\%) is $20.96 \pm 3.85 \%$, and the percentage of muscle mass (MUSC\%) is $34.68 \pm 1.83 \%$. It is obvious that there are significant differences in the body composition of the participants.

Table 1. Dispersal indicators of body composition, functional abilities and results in apnea in participants

\begin{tabular}{ccccccc}
\hline Var & Min & Max & Mean & SD & Skew & Kurt \\
\hline HB & 149 & 172 & 162.98 & 5.25 & -.61 & .11 \\
BM & 40 & 62 & 51.47 & 5.57 & -.05 & -.74 \\
BMI & 16 & 24 & 19.22 & 1.66 & .61 & 1.04 \\
BODF & 11 & 27 & 20.96 & 3.85 & -.65 & .19 \\
MUSC & 31 & 39 & 34.68 & 1.83 & -.06 & -.29 \\
FVC & 3 & 5 & 4.06 & .36 & .23 & .11 \\
FEV & 3 & 4 & 3.72 & .32 & -.23 & -.94 \\
STA & 42 & 128 & 87.23 & 20.70 & -.06 & -.29 \\
DNF & 30 & 73 & 44.94 & 11.32 & .97 & .34 \\
\hline
\end{tabular}

Legend: Arithmetic Mean, Standard Deviation (SD), Skewness (Skew.), Kurtosis (Kurt.).

The minimum and maximum values of the functional ability estimates indicate that the values are in the expected range. The results achieved in static apnea are on average $87.23 \mathrm{sec}$, while in dynamic apnea the results range from $30 \mathrm{~m}$ to $73 \mathrm{~m}$, which indicates a great difference in the results achieved among the examinees. 
Table 2. Regression analysis of the predictor system and the criterion variable STA

\begin{tabular}{ccccccc}
\hline Model & $\mathrm{R}$ & R Square & $\begin{array}{c}\text { Adjusted R } \\
\text { Square }\end{array}$ & $\begin{array}{c}\text { Std. Error of the } \\
\text { Estimate }\end{array}$ & F & Sig. \\
\hline 1 & $.60^{\mathrm{a}}$ & .36 & .26 & 17.87 & 3.32 & $.02^{\mathrm{a}}$ \\
\hline \multicolumn{7}{l}{ Legend: $R$ - multi-correlation coefficient, $R 2$ - multi-correlation coefficient coefficient, }
\end{tabular}
Adjusted R Square - corrected coefficient of multiple correlation determination, Std. Error of the Estimate. - standard forecast error, F - value of F test, which tests the significance of the predictor community with the criterion variable, $p$ - level of significance of the multicorrelation coefficient; Predictors: BMI, BODF, MUSC

The relationships between morphological characteristics, functional ability of swimmers, and criterion variables STA are shown in Table 2. The obtained coefficient of multiple correlation $\mathrm{R}=.36$ indicates that the system of predictor variables has a significant influence on achieving success in apnea. The common variability between the predictor system and the criterion variable is $36 \%\left(\mathrm{R}^{2}=.36\right)$. The remaining $64 \%$ in explaining the overall variability can be attributed to other abilities and characteristics of subjects, which were not applied in this regression analysis.

Table 3. Regression analysis of the predictor system and the criterion variable DNF

\begin{tabular}{ccccccc}
\hline Model & $\mathrm{R}$ & R Square & $\begin{array}{c}\text { Adjusted R } \\
\text { Square }\end{array}$ & $\begin{array}{c}\text { Std. Error of the } \\
\text { Estimate }\end{array}$ & F & Sig. \\
\hline 1 & $.55^{\mathrm{a}}$ & .31 & .19 & 10.13 & 2.58 & $.05^{\mathrm{a}}$ \\
\hline
\end{tabular}

Table 3 shows the results of the connection of the predictor system of variables for the assessment of morphological characteristics and functional abilities with the dependent variable DNF. By analyzing the obtained results, it can be concluded that there is a statistically significant connection between the predictor system and the criteria $(\mathrm{p}=.05)$. The relationship between the predictor system and the criterion variable explains the coefficient of multiple 
correlation $(\mathrm{R}=.55)$ as well as the coefficient of determination $\left(\mathrm{R}^{2}=.31\right)$ indicating $30 \%$ of the total information.

Table 4. Partial regression indicators in the latent space of the body composition, the functional ability of the egg yarn - DNF

\begin{tabular}{cccccc}
\hline Var. & B & Std. Error & Beta & t & Sig. \\
\hline BMI & -2.51 & 1.42 & -.37 & -1.76 & .09 \\
BODF & 2.77 & 1.13 & .95 & 2.45 & .02 \\
MUSC & 5.46 & 2.06 & .89 & 2.65 & .01 \\
FVC & 21.62 & 8.99 & .69 & 2.40 & .02 \\
FEV & -21.22 & 9.87 & -.61 & -2.15 & .04 \\
\hline
\end{tabular}

The individual contribution of body composition and functional abilities to the results achieved in the DNF discipline (dynamic apnea without fins) is shown in Table 4. The results showed a positive association of body fat (BODF) with a statistical significance of $p=.02$, a percentage of muscle mass (MUSC), with a significance level of $\mathrm{p}=0.13$, forced vital capacity $(\mathrm{p}=.02)$ and forced expiratory volume $(\mathrm{p}=.04)$.

\section{Discussion}

The achieved result in a sport is the best indicator of the overall sporting form. However, the achieved result only cannot provide enough information and does not reveal the weak links in the overall chain of apneas preparation. It is necessary to create a gathering information system about all indicators on which the final results depend, in order to correct the training program. The results of this research are one of the starting points and ideas for further studies in this field. Breath holding and staying underwater cause certain physiological reactions in the apneas. The unique aspect of diving is the period of time spent on breath holding while performing underwater movement (DNF) or floating (STA). The body composition is a key component in diving. Data about the extremity's length and proportions, bone diameter, percentages of muscle mass, and the percentage of body fat in the diver, could provide a better understanding of the optimal anthropometric characteristics for this sport. 
The descriptive statistics results indicate a large range between the obtained minimum and maximum results, which confirms the conclusion that growth and development at this age resulted in apparent differences in the subjects body composition. If we compare the obtained data with the international "Cut off points" table defining body weight and obesity, we note that the mean values of subjects are in the health zone. More fat values in the body (27\%) and a higher range of muscle mass percentages from $31 \%$ to $39 \%$ can be noticed in some subjects. Body shape is not an element for trail in apnea, but the appearance and body composition are in the focus of the coach and athlete. In addition to intensive training and nutritional requirements for athletes in apnea are also complex (Fortes, Neves, Filgueiras, Elisa, \& Ferreira, 2013; Robertson, Benardot, \& Mountjoy, 2014a; Sundgot-Borgen \& Garthe, 2011).

In the competitors respiratory function testing, normal values were found in the parameters: forced vital capacity (FVC), forced expiratory volume (FEV).Despite apparent ease, diving represents a rather demanding sport - in addition to serious physical preparation requires the mastering of breath control skills (Alentejano, Marshall, \& Bell, 2010; Homma, 2010; Quan et al., 2010; Robertson et al., 2014a). There are great differences in functional abilities among subjects. Some of the subjects achieved high test results (STA) in static apnea (128s) and (DNF) dynamic apnea without fins (73m). The differences between subjects indicate great differences in the swimmers preparing system in terms of functional abilities. Some subjects show very low functional abilities results.

The relationship of the variables system for morphological characteristics and functional abilities assessment with the dependent variable STA (Table 2) is relatively high $(\mathrm{R}=.60)$. By analyzing the obtained results, it can be concluded that there is a statistically significant relationship between the predictor system and the criteria $(\mathrm{p}=.02)$. Comparing results of forced vital capacity and forced expiratory volume between divers (men and women), water polo players, swimmers and control groups of respondents also found that the results in these parameters show significant differences in the benefit of all athletes. The best results among athletes had divers. The largest individual contribution to achieving the best results in static apnea has: a body mass index with a statistical significance level of $\mathrm{p}=0.02$ and an amount of fat in the body with a statistical significance level of $p=039$. On this sample of subjects, the results showed a positive correlation between the amount of fat in the body and the resultant efficacy.

It is not difficult to explain these results with regard to the static apnea characteristics. The amount of fat in the body should not always be regarded as a negative feature. Body fats have lower water density and therefore a higher percentage of fat in the body ensures that most 
of the body is above the water surface (Andersson, 2003; Tocco et al., 2012), which is very important for this competition discipline. These results suggest that it is necessary to apply the BIA method in testing athletes who practice apnea in all categories. On the basis of the results obtained, more concrete conclusions can be drawn regarding the body composition of these athletes. A large number of research should be directed to all anthropometric characteristics of these athletes, and the sports nutrition aspects that can be of great importance for this kind of sport.

The morphological characteristics and functional abilities connection with resultant efficacy in disciplines DNF (dynamic apnea without fins) suggests that predictor variables have a significant impact on achieving success in dynamic apnea $(\mathrm{R}=.55)$. The determination coefficient $\left(\mathrm{R}^{2}=.31\right)$ indicates $30 \%$ of the total information.

The need for food in apnea competitors varies considerably from the needs of athletes in other sports, as energy resources in diving must be maximized to achieve maximum results. Earlier research (Schagatay, 2014) suggests that achieving better results in apnea is associated with athletes' nutrition. Many authors' researches confirm that the morphological characteristics of the body are one of the prerequisites for achieving better competitive results (Robertson et al., 2014a; Tanaka et al., 2006; Yamamura et al., 1999). The collected data show that apnea competitors who have a higher percentage of muscle mass and body fat make better results. The results of this study show that there is an effect of the amount of fat in the body (with statistical significance of $p=.02$, Table 4) and the percentage of muscle mass (with significance of $\mathrm{p}=.01$ ) on success in dynamic apnea. The body composition quantification and muscle characteristics are of great benefit to apnea competitors. The body composition is not related to the mode of diving, but that the dive duration has a different effect on the body composition of men and women. Numerous anatomical and physiological features combine to give competitors this "diving power". This ability has been studied by many researchers (Ferretti \& Costa, 2003; Magnani et al., 2018) for many years, and it is evident that apnea training can increase the individual competitors underwater performances (Schagatay, 2014). All previous research in this field suggests that monitoring the body composition of athletes who practice apnea is necessary at all stages of the competitors condition control.

Cardiovascular and functional changes in humans during apnea diving are only partially known because of technical difficulties in studying fully immersed subjects. Researchers' efforts in this field are great. Some research refers to the functional ability's assessment on dry and then in water. Swimmers who are trained to work in apnea have a great advantage over untreated ones (Alentejano et al., 2010). The study showed that bradycardia appeared in 
swimmers, while there were no significant changes in the control group. Increased breathholding ability and lower pulse during recovery suggest a better adaptation of the swimmers compare to the control group examinees. The vital capacity of artistic swimmers during the composition performance is very high $(82-85 \% \mathrm{VO} 2 \mathrm{max})$ and that there are no differences between the junior and cadet categories in the VO2max values when performing the composition. Diving as a sport with extremely demanding technique and underwater movements requires intensive preparation of swimmers, especially in terms of functional abilities. It is necessary to include all exercises with longer retention in apnea in the training process, which would contribute to increasing the level of functional abilities, bearing in mind that a large number of studies (T. C. Alentejano et al., 2010; Orellana et al., 2006; Quan et al., 2010) confirms that the functional abilities have crucial significance for the resultant efficiency. Researchers also indicates that functional abilities are correlated with competitive results. The results of their research show that specific training processes contribute to great differences in functional abilities compared to those of the same age who are not in the training process.

Lung function greatly contributes to competing achievements (Trassinelli, 2016). Respiratory organs adaptation is present in all diving techniques in which athletes practicing apnea control their breath. All this contributes to the vital capacity increase in divers. In the study of vital capacity in elite divers (Erika Schagatay \& Lodin-Sundström, 2014) by analyzing the results obtained suggests that the lungs volume was on average greater by 1.81 in divers than non-diving subjects. The results obtained in this study indicate that a statistically significant part in the achieved results in dynamic apnea (DNF) was achieved in the variables FVC (with the level of statistical significance p=.023) and FVC (with the level of statistical significance $\mathrm{p}=.040$ ). Changes in the functional abilities of apnea competitors in this study provide useful information to improve apnea training. The primary goal should be achieved by training in static apnea in order to extend the dive time. Adaptation processes that are the result of continuous exposure to underwater apnea lead to an increase in lung capacity (Trassinelli, 2016). Secondly, inherently dynamic apnea is work on technique to save and reduce unnecessary energy consumption.

\section{Conclusion}

The ability of the human body to adapt, transform and increase its capabilities continues to surprise. Diving in apnea is a complex sport that remains relatively not explored in literature. There are a few papers with women's population. There are almost no papers related to the morphology and functioning of the female organism and it is known that this is a specific and insufficiently investigated area in all sports, especially in apnea. Many studies that have been 
conducted in this sport have methodological limitations. The need for very precise interpretation and application of the smallest details related to apnea training, which were neglected by the trainers, was emphasized. In this research, we tried to emphasize the significance of the body composition and functional abilities in achieving competitive results in apnea. Although this is a selected sample of subjects, it is obvious that they differ significantly both in morphological and functional abilities. In the area of morphological characteristics there is a statistically significant correlation between the applied tests and criteria in the variables of BMI and BODF. However, our understanding of female lung response to apnea work remains incomplete. In order to fully address the relationship between morphological characteristics and functional abilities and work in apnea, future research should focus on comparison of the relationship between subjects in different age, with different body weight and lung capacity. Future studies should try to explain in more detail the abilities of athletes that work in apnea, both static and dynamic apnea. Based on the obtained results, an adequate training process can be formed. The results of this research can find a wide practical application in the physical preparation of athletes who practice exercises in apnea. The fact is that further advances in science will allow a better understanding of the organism function in apnea. Discovering new scientific achievements within this sport or the use of better training means will contribute to a more qualitative preparation of competitors and thus enable top results achievement. With the development of new research technologies, new opportunities for improving the way of obtaining information relevant to the sport system are being created.

\section{Acknowledgements}

There has been no financial assistance with the project.

\section{References}

Alentejano, T., Bell, G., \& Marshall, D. (2012). A Comparison of the Physiological Responses to Underwater Arm Cranking and Breath Holding Between Synchronized Swimmers and Breath Holding Untrained Women. Journal of Human Kinetics, 32(1). https://doi.org/10.2478/v10078-012-0031-7

Alentejano, T. C., Marshall, D., \& Bell, G. J. (2010). Breath holding with water immersion in synchronized swimmers and untrained women. Research in Sports Medicine, 18(2), 97114. https://doi.org/10.1080/15438620903323678

Andersson, J. P. A. (2003). Cardiovascular and respiratory responses to apneas with and without face immersion in exercising humans. Journal of Applied Physiology, 96(3), 10051010. https://doi.org/10.1152/japplphysiol.01057.2002

Armstrong, N., Tomkinson, G., \& Ekelund, U. (2011). Aerobic fitness and its relationship to 
sport, exercise training and habitual physical activity during youth. British Journal of Sports Medicine, 45(11), 849-58. https://doi.org/10.1136/bjsports-2011-090200

Benefice, E., \& Malina, R. (1996). Body size, body composition and motor performances of mild-to-moderately undernourished Senegalese children. Annals of Human Biology, 23(4), 307-321. https://doi.org/10.1080/03014469600004542

Dodigović, L., \& Sindik, J. (2015). COMPARISON OF SELECTED HEALTH AND MORPHOLOGICAL PARAMETERS BETWEEN CLASSIC SWIMMING AND SYNCHRONIZED SWIMMING. Sport Scientific \& Practical Aspects, 12(2), 5-9. Retrieved from http://search.ebscohost.com/login.aspx ?direct=true \&db=s3h\&AN=112226865\&lang= pt-br\&site $=$ ehost-live

Ferretti, G., \& Costa, M. (2003). Diversity in and adaptation to breath-hold diving in humans. Comparative Biochemistry and Physiology - A Molecular and Integrative Physiology. https://doi.org/10.1016/S1095-6433(03)00134-X

Fortes, L. D. S., Neves, C. M., Filgueiras, J. F., Elisa, M., \& Ferreira, C. (2013). Body dissatisfaction, psychological commitment to exercise and eating behavior in young athletes from aesthetic sports. Brazilian Journal of Kineanthropometry \& Human Performance, 15(March), 695. https://doi.org/10.5007/1980-0037.2013v15n6p695

Hayriye Çakır, A. (2017). The effects of swimming training on selected strength and respiratory function variables in pre-pubertal children. Journal of Athletic Performance and Nutrition (JAPN), 4(1), 17-33.

Homma, M. (2010). Relationship between Eggbeater Kick and Support Scull Skills, and Isokinetic Peak Torque. XIth International Symposium for Biomechanics \& Medicine in Swimming, 91-93.

Retrieved

from http://search.ebscohost.com/login.aspx ?direct=true \&db=s3h\&AN=82876617\&lang=pt -br\&site=ehost-live

Kafkas, A. Ş., Eken, Ö., Fahri Safa, Ç., \& Kafkas, E. (2016). Acute Effect of Static Warm-up Duration on 50 Meter Freestyle and Breaststroke Performance. Journal of Athletic Performance and Nutrition, 2(3), 1-10.

Lindholm, P., \& Lundgren, C. E. (2008). The physiology and pathophysiology of human breathhold diving. Journal of Applied Physiology, 106(1), 284-292. https://doi.org/10.1152/japplphysiol.90991.2008

Magnani, S., Mulliri, G., Sainas, G., Ghiani, G., Pinna, V., Sanna, I., ... Tocco, F. (2018). Occurrence of cardiac output decrease (via stroke volume) is more pronounced in 
women than in men during prolonged dry static apnea. Journal of Applied Physiology, 124(2), 349-355. https://doi.org/10.1152/japplphysiol.00991.2016

Orellana, J. N., Centeno, R. A., Carranza, M. D., \& Cayetano, M. (2006). A test for evaluation of exercise with apneic episodes in synchronized swimming. International Journal of Sports Medicine, 27(12), 1000-1004. https://doi.org/10.1055/s-2006-923846

Pyne, D. B., \& Sharp, R. L. (2014). Physical and energy requirements of competitive swimming events. In International Journal of Sport Nutrition and Exercise Metabolism (Vol. 24, pp. 351-359). https://doi.org/10.1123/ijsnem.2014-0047

Quan, L., Culver, B. H., Fielding, R., Quan, L. ; Culver, B. H. ; Culver, B., \& Fielding, R. R. (2010). Hypoxia-Induced Loss of Consciousness in Multiple Synchronized Swimmers During a Workout. International Journal of Aquatic Research and Education International Journal of Aquatic Research and Education International Journal of Aquatic Research and Education, 4(4), 379-389. Retrieved from http://scholarworks.bgsu.edu/ijare\%5Cnhttp://scholarworks.bgsu.edu/ijare

Robertson, S., Benardot, D., \& Mountjoy, M. (2014a). Nutritional recommendations for synchronized swimming. International Journal of Sport Nutrition and Exercise Metabolism, 24(4), 404-13. Retrieved from http://www.ncbi.nlm.nih.gov/pubmed/24667278

Robertson, S., Benardot, D., \& Mountjoy, M. (2014b). Nutritional recommendations for synchronized swimming. In International Journal of Sport Nutrition and Exercise Metabolism (Vol. 24, pp. 404-413). https://doi.org/10.1123/ijsnem.2014-0013

Robinson, K., \& Ferraro, F. R. (2004). The relationship between types of female athletic participation and female body type. The Journal of Psychology, 138(2), 115-128. https://doi.org/10.3200/JRLP.138.2.115-128

Schagatay, E. (2014). Human breath-hold diving ability and the underlying physiology. Human Evolution, 29(1-3), 125-140.

Schagatay, E., \& Lodin-Sundström, A. (2014). Fasting improves static apnea performance in elite divers without enhanced risk of syncope. European Journal of Sport Science, 14(SUPPL.1). https://doi.org/10.1080/17461391.2012.664172

Stanković, S., Milanović, S., \& Marković, Ž. (2015). USE OF BASIC SYNCHRONISED SWIMMING TECHNIQUES IN NON-SWIMMERS TRAININGS. Activities in Physical Education \& Sport, 5(1), 82-85. Retrieved from http://search.ebscohost.com/login.aspx ?direct=true \&db=s3h\&AN=108408291\&lang= pt-br\&site=ehost-live 
Sundgot-Borgen, J., \& Garthe, I. (2011). Elite athletes in aesthetic and Olympic weight-class sports and the challenge of body weight and body composition. Journal of Sports Sciences, 29(SUPPL. 1). https://doi.org/10.1080/02640414.2011.565783

Tanaka, C., Iida, T., Tawara, Y., Murata, M., Takamatsu, J., Homma, M., \& Kawahara, T. (2006). Characteristics of bone density in adolescent synchronized swimmers Relationships between bone density, daily physical activity and dietary intake. JAPANESE JOURNAL OF PHYSICAL FITNESS AND SPORTS MEDICINE, 55(1), 165-173.

Tocco, F., Crisafulli, A., Melis, F., Porru, C., Pittau, G., Milia, R., \& Concu, A. (2012). Cardiovascular adjustments in breath-hold diving: Comparison between divers and nondivers in simulated dynamic apnoea. European Journal of Applied Physiology. https://doi.org/10.1007/s00421-011-2006-0

Trassinelli, M. (2016). Energy cost and optimisation in breath-hold diving. Journal of Theoretical Biology, 396, 42-52. https://doi.org/10.1016/j.jtbi.2016.02.009

Vaithiyanadane, V., Sugapriya, G., Saravanan, A., \& Ramachandran, C. (2012). The diffusing lung capacity in swimmers and non-swimmers: A comparative study. Journal of Clinical and Diagnostic Research, 6(4 SUPPL. 2), 586-589.

Winiarski, S., Dubiel-Wuchowicz, K., \& Rutkowska-Kucharska, A. (2013). Symmetry of support scull and vertical position stability in synchronized swimming. Acta of Bioengineering and Biomechanics, 15(1), 113-122. https://doi.org/10.5277/abb130114 Yamamura, C., Zushi, S., Takata, K., Ishiko, T., Matsui, N., \& Kitagawa, K. (1999). Physiological characteristics of well-trained synchronized swimmers in relation to performance scores. International Journal of Sports Medicine, 20(4), 246-251. https://doi.org/10.1055/s-2007-971125 